Moisture desorption rates from

TATB-formulations: experiments and kinetic models

E. A. Glascoe, L. N. Dinh, W. Small, G. E. Overturf

February 14,2012

Journal of Physical Chemistry B 
This document was prepared as an account of work sponsored by an agency of the United States government. Neither the United States government nor Lawrence Livermore National Security, LLC, nor any of their employees makes any warranty, expressed or implied, or assumes any legal liability or responsibility for the accuracy, completeness, or usefulness of any information, apparatus, product, or process disclosed, or represents that its use would not infringe privately owned rights. Reference herein to any specific commercial product, process, or service by trade name, trademark, manufacturer, or otherwise does not necessarily constitute or imply its endorsement, recommendation, or favoring by the United States government or Lawrence Livermore National Security, LLC. The views and opinions of authors expressed herein do not necessarily state or reflect those of the United States government or Lawrence Livermore National Security, LLC, and shall not be used for advertising or product endorsement purposes. 


\title{
Moisture desorption rates from TATB-formulations: experiments and kinetic models
}

\author{
Elizabeth A. Glascoe*, Long N. Dinh, Ward Small IV, George E. Overturf III
}

Lawrence Livermore National Laboratory, 7000 East Ave., Livermore, CA, 94550.

\author{
glascoe2@1lnl.gov
}

RECEIVED DATE (to be automatically inserted after your manuscript is accepted if required according to the journal that you are submitting your paper to) 


\begin{abstract}
The rate of water desorption from PBX-9502, a formulation containing 1,3,5-triamino-2,4,6trinitrobenzene (TATB), is measured using temperature programmed desorption and modeled using conventional kinetic modeling methods. The results of these studies show two stages of moisture release. At lower temperatures, the release is likely assisted by thermal expansion of the TATB and melting of the Kel-F binder. At higher temperatures, a considerable amount of water is released and is attributed to sublimation of the TATB which exposes new surfaces for water desorption.
\end{abstract}

KEYWORDS TATB, moisture, explosive, kinetics, desorption 


\section{INTRODUCTION}

Numerous studies have probed the chemical mechanisms of initiation and reaction of the energetic material 1,3,5-triamino-2,4,6-trinitrobenzene (TATB). Currently, there are two plausible mechanisms under debate: (1) the inter/intramolecular $\mathrm{H}$-atom $\operatorname{transfer}^{1-6}$ and (2) the $\mathrm{C}-\mathrm{NO}_{2}$ bond homolysis or rearrangement (which includes the nitro-nitrite isomerization mechanisms)..$^{2,5,7-11}$ Numerous studies have investigated the validity of these two mechanisms and careful research has validated each of these mechanisms. Such a scenario indicates that the chemical mechanism(s) of TATB are complex and depend heavily on the conditions (e.g. temperature, heating rate, pressure, etc).

One of the main products of the inter/intramolecular H-atom transfer mechanism is water. As such, the presence of water molecules in the reaction products has been taken as evidence that the mechanism was accessed in the reaction. One weakness of this approach is the fact that TATB and its formulations typically have water ad/absorbed into the material that could be released prior to or during decomposition. Teasing out the mechanisms that produce water via desorption versus the mechanisms that produce water via material decomposition can be challenging and a study of the moisture desorption rates prior to decomposition is necessary.

Here we have quantified and characterized the rate of moisture release from the TATB formulation PBX-9502 (95\% TATB, 5\% Kel-F 800) prior to decomposition. PBX-9502 is a heterogeneous material with many different potential sources and mechanisms of water release. Water molecules could be ad/absorbed into the polymeric binder matrix, trapped in occlusions within the polymer and the TATB crystals/particles, or trapped within defect sites in the TATB crystal. Using temperature programmed desorption (TPD) coupled with mass spectrometry, the rate and amount of water released as a function of temperature was monitored. The experimental data was analyzed using two different kinetic analysis methods (isoconversional analysis and $\mathrm{n}^{\text {th }}$-order Arrhenius kinetic fits). The resulting models were compared with the results of previous oven-drying studies. This work not only allows for a reinterpretation of some of the existing decomposition studies, but supplies future studies with guidance on the rates and possible mechanisms of moisture release prior to decomposition. 


\section{EXPERIMENTAL}

For a typical TPD experiment, PBX-9502 powder $(<10 \mathrm{mg})$ was wrapped inside a Pt foil envelope. The side of the envelope facing the mass spectrometer was perforated with pin holes over its entire surface. The loaded foil was attached to a sample holder by way of mechanical clamps and transferred into an ultrahigh vacuum (UHV) chamber with a base pressure of $10^{-6} \mathrm{~Pa}\left(4 \times 10^{-7} \mathrm{~Pa}\right.$ in the mass spectrometer chamber) through a differentially pumped load lock. The sample temperature was measured using a type $\mathrm{K}$ thermocouple inserted between the Pt envelope front surface and one of the clamps holding the envelope. The sample was then pumped in the UHV chamber for 3 hours at room temperature to remove $\mathrm{H}_{2} \mathrm{O}$ molecules that were loosely bonded to the powder. The detector chamber is equipped with a quadrupole mass spectrometer (QMS) and has been described in detail elsewhere. ${ }^{12}$

Heating of the sample was done by passing current through a tungsten coil located $2 \mathrm{~mm}$ behind the sample. Samples were heated at five different heating rates $\left(0.005^{\circ} \mathrm{C} / \mathrm{s}, 0.0075^{\circ} \mathrm{C} / \mathrm{s}, 0.0125^{\circ} \mathrm{C} / \mathrm{s}, 0.025\right.$ ${ }^{\circ} \mathrm{C} / \mathrm{s}$ and $0.15^{\circ} \mathrm{C} / \mathrm{s}$ ). The maximum temperature was limited in order to ensure little to no sample decomposition in these experiments. The maximum temperature ranged from $238{ }^{\circ} \mathrm{C}$ at the slowest heating rate to $290{ }^{\circ} \mathrm{C}$ at the fastest. According to differential scanning calorimetry (DSC) measurements, at the slowest heating rate TATB begins to decompose at $\sim 310{ }^{\circ} \mathrm{C}$ and at the highest heating rate it begins to decompose at $\sim 347^{\circ} \mathrm{C}$. Hence, in these experiments we are $60-70{ }^{\circ} \mathrm{C}$ below the onset of TATB decomposition, and we believe the water observed in these studies is latent water within the material, not a product of decomposition. Assuming that no water was produced by decomposition and that all trapped water was released, the initial water concentration in the sample was approximately $0.15-0.28 \%$ by weight based on the total amount of water measured in the TPD experiments. The range in moisture is due to the variability from sample to sample used for each heating rate; no systematic shift in moisture outgassing was observed as a function of heating rate.

The water outgassing kinetics were obtained via two different kinetic analysis methods: the isoconversional method by Friedman and a simple $\mathrm{n}^{\text {th }}$-order Arrhenius analysis. Both methods are 
described in detail in the literature. ${ }^{13-15}$ Briefly, in both methods the rate equation for fraction reacted begins with:

$$
\frac{d \alpha}{d t}=k f(\alpha)=A e^{-E / R T} f(\alpha)
$$

where $\alpha$ is fraction reacted (ranging from 0 to 1 ), $t$ is time, $k$ is the Arrhenius rate constant, $A$ is the pre-factor, $E$ is the activation energy, $R$ is the gas constant, $T$ is temperature, and $f(\alpha)$ is the reaction model. In the Friedman isoconversional method, equation (1) is transformed to the following:

$$
\ln \left(\frac{d \alpha}{d t_{\alpha}}\right)=\frac{-E_{\alpha}}{R T_{\alpha}}+\ln \left[A_{\alpha} f(\alpha)\right]
$$

By plotting $\ln \left(\mathrm{d} \alpha / \mathrm{dt}_{\alpha}\right)$ versus $1 / T_{\alpha}$ (i.e. the reciprocal temperature at each fraction point, $\alpha$ ) and fitting the data to a line, the values for $\mathrm{E}_{\alpha}$ and $\ln \left[\mathrm{A}_{\alpha} \mathrm{f}(\alpha)\right]$ can be calculated. These values are dependent on the extent of the reaction. To make a prediction at a chosen isothermal temperature $\left(T_{0}\right)$ one must simply integrate equation (1) and use the values for $\mathrm{E}_{\alpha}$ and $\ln \left[\mathrm{A}_{\alpha} \mathrm{f}(\alpha)\right]$ from equation (2). The time integral at isothermal temperature is:

$$
t_{\alpha}=\int_{0}^{t_{\alpha}} d t=\int_{0}^{\alpha} \frac{d \alpha}{\left[A_{\alpha} f(\alpha)\right] e^{-E_{\alpha} / R T_{o}}}
$$

In the $\mathrm{n}^{\text {th }}$-order Arrhenius analysis, a two-stage Arrhenius form of equation (1) was used:

$$
\frac{d \alpha}{d t}=w_{1} k_{1} f_{1}(\alpha)+w_{2} k_{2} f_{2}(\alpha)=w_{1} A_{1} e^{-E_{1} / R T}(1-\alpha)^{n_{1}}+w_{2} A_{2} e^{-E_{2} / R T}(1-\alpha)^{n_{2}}
$$

where the subscript numbers are used for indexing purposes only and $w$ corresponds to a weighting factor. To make a prediction using this model, one must simply apply the derived kinetic parameters from a prior fit (i.e. A, E, and n) and introduce the desired temperature or temperature profile. Fits and predictions using the $\mathrm{n}^{\text {th }}$-order Arrhenius model were performed using the program Kinetics $05 .{ }^{16}$

\section{RESULTS AND DISCUSSION}

\section{Water Desorption Dynamics and Mechanisms}


Figure 1 shows the fraction of water released $(\alpha)$ as a function of temperature as measured in the TPD experiment. It is clear in this figure that there are two regimes. At lower temperatures $\left(<125^{\circ} \mathrm{C}\right)$ the water release accelerates then stabilizes to a steady rate. The majority of the water is released at the higher temperatures (i.e. $>175^{\circ} \mathrm{C}$ ). The two distinct regimes observed in Figure 1 are probably due to different phenomena involving changes in the material state that create new pathways for the water to escape.

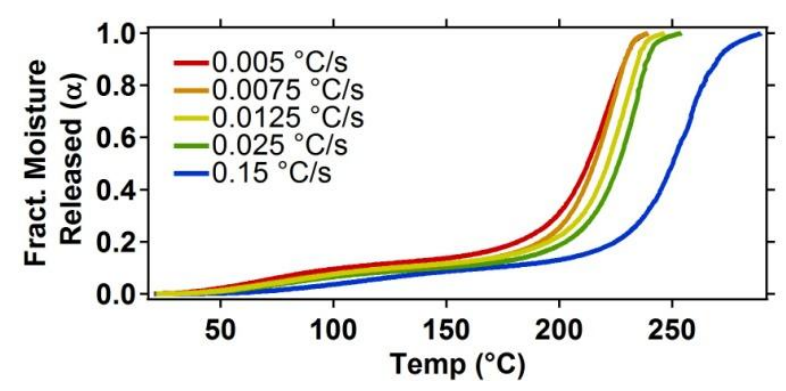

FIGURE 1. Fraction of total water release as a function of temperature at various heating rates.

Under the conditions of the experiments (i.e. sub-ambient pressures and elevated temperatures) both the TATB and Kel-F 800 binder undergo various changes of state including phase transitions, thermal expansion and sublimation. All of these processes facilitate the escape of water molecules that may be deeply embedded in the material. Kel-F 800 undergoes a glass transition at approximately $30{ }^{\circ} \mathrm{C}$ and melts at approximately $95{ }^{\circ} \mathrm{C}$, both transition temperatures vary slightly by sample. ${ }^{17}$ Each transition increases the mobility of the polymer, potentially creating new pathways for water molecules to diffuse out of the material. These phase transitions could be partially responsible for the two-stage kinetics of water outgassing observed in Figure 1.

Both the binder and TATB experience thermal expansion, and TATB-formulations demonstrate significant volume expansion between ambient and $250{ }^{\circ} \mathrm{C} .{ }^{17-19}$ The heterogeneous nature of TATB/Kel-F 800 formulations cause the thermal expansion of the constituent materials to expose new surfaces via cracks and voids in the material. ${ }^{20}$ These new surfaces may have water molecules embedded in them and the newly formed cracks and voids facilitate water transport through the 
material. This process will occur over the entire temperature range and cannot be assigned to any specific stage in the water outgassing dynamics shown in Figure 1.

At the higher temperatures, TATB sublimation is a likely process. The reported vapor pressure for TATB between 130 and $200{ }^{\circ} \mathrm{C}$ is significantly higher $(1-4$ orders of magnitude, respectively) than the static pressure inside the UHV sample chamber. ${ }^{21}$ Sublimation of TATB at these higher temperatures will expose new surfaces and, consequently, enable the release of tightly bound molecules of water. Sublimation would explain the rapid and relatively large volume of water released during the second stage of the TPD experiments in Figure 1.

\section{Kinetics Analysis}

Two different kinetic analysis methods were applied to this data, the $\mathrm{n}^{\text {th }}$-order Arrhenius model and Friedman's isoconversional model. The kinetic parameters from the $\mathrm{n}^{\text {th }}$-order Arrhenius model are listed in Table I. Because of the two distinct regimes observed in Figure 1, the data were fit to a two-stage kinetic model consisting of two rates and two sets of Arrhenius parameters. A comparison of the $n^{\text {th }}$ order fit with the experimental data is shown in Figure 2(b). As expected, the first activation barrier (E) is lower than the second; however, the first frequency factor (A) is also quite a bit lower than the second. Typically, a higher frequency factor results in an accelerated rate; hence a low frequency factor will attenuate the effects of a low activation barrier. It is noteworthy that the reaction order (n) for the first reaction is quite large relative to the second; these reaction orders may provide clues to the mechanisms underlying these two kinetic regimes. In general, the fits of the model to the data were quite good, indicating that the kinetic parameters accurately represent the data. 


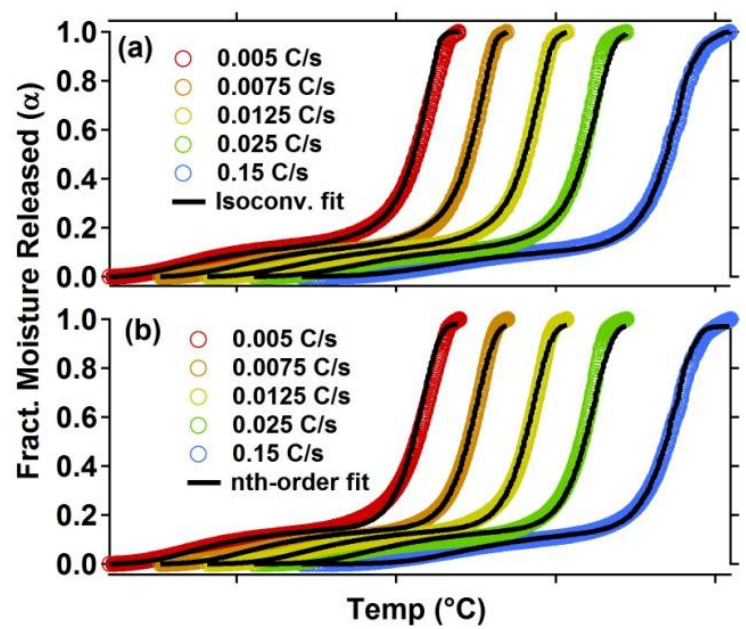

FIGURE 2. Comparison of (a) isoconversional and (b) nth-order predictions with raw data for the moisture outgassing from PBX-9501. Curves were horizontally shifted for better visualization of every curve; see Figure 1 for the true temperature scale.

Table I. Arrhenius parameters for an $n^{\text {th }}$-order fit to the moisture outgassing data. Refer to equation 4 for an explanation of variables.

\begin{tabular}{lll}
\hline \hline & Index 1 & Index 2 \\
\hline $\mathrm{A}(1 / \mathrm{s})$ & $2.5 \mathrm{E}+07$ & $8.3 \mathrm{E}+15$ \\
$\mathrm{E}(\mathrm{kJ} / \mathrm{mol})$ & 72 & 180 \\
$\mathrm{n}$ & 5.8 & 1 \\
$\mathrm{w}$ & 0.19 & 0.81 \\
\hline
\end{tabular}

The reaction orders provided by the $\mathrm{n}^{\text {th }}$-order Arrhenius analysis provide some clues to the mechanisms. As discussed above, the first stage of water release (i.e. the lower temperature regime) may be due to increased mobility of the Kel-F 800 binder. The high reaction order (5.8) for this stage, is indicative of a complex mechanism for water release. A reaction order of $n>1$ corresponds to a gamma distribution of reactivity $^{22}$ and was used to represent a distribution of diffusion lengths in sintering problems. $^{23}$ If the water molecules in our system are navigating the dynamic environment of a semiamorphous polymer matrix above its glass transition temperature, the water release rate may have a high 
reaction order, which may be partially attributed to a distribution of diffusion lengths. In contrast, the second stage of water release (i.e. the higher temperature regime in Figure 1) has a reaction order of 1.0. As TATB sublimes, new surfaces are exposed, most likely along the outer surface area of the PBX-9502 particles and the release of water would only be limited by the rate of desorption. The enthalpy of sublimation of TATB is $167.7 \mathrm{~kJ} / \mathrm{mol}^{24}$ which is a close match with the activation energy measured in this work $(180 \mathrm{~kJ} / \mathrm{mol})$ for the second stage of moisture release. In addition, water desorption from a surface is a first order reaction process (i.e., $\mathrm{n}=1) .{ }^{25}$ Hence, the most plausible mechanism is that the high barrier process corresponds to the sublimation of TATB, which then exposes new surfaces from which the moisture can rapidly and easily desorb.

The results of the isoconversional analysis are shown in Figure 3 and a comparison of the fit to the experimental data is shown in Figure 2(a). Because this analysis method provides a fraction-dependent activation energy and value for $\ln \left[\mathrm{A}_{\alpha} \mathrm{f}(\alpha)\right]$ the data is best presented in a figure (refer to supplementary information for tabular data). According to the results in Figure 3, the activation energy drops during the first $10 \%$ of the reaction and then rises again up to the $20 \%$ mark. Between $20 \%$ and $80 \%$ the activation energy is relatively stable and is quite similar to the second activation energy in our $\mathrm{n}^{\text {th }}$-order fit (Table I, index 2).

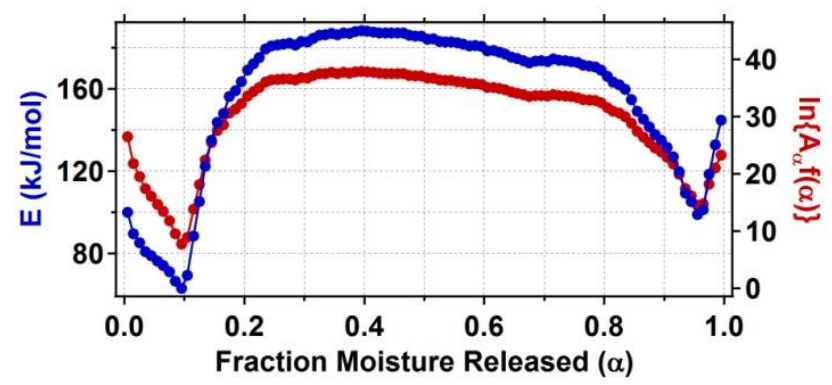

FIGURE 3. Isoconversional fit parameters as a function of fraction reacted.

The two kinetic models both gave similar results and each model has strengths and weaknesses. The power of any kinetic model is the ability to use it to predict a reaction using a novel thermal profile. For example, using these ramped heating experiments one might ask if the derived kinetic variables can predict water release after heating at a mild temperature for days or weeks. The advantage of the 
isoconversional approach is that there is no assumption of the model made; instead, it limits the assignment of kinetic variables to a specific fraction reacted, i.e., $\alpha$. In contrast, the $\mathrm{n}^{\text {th }}$-order Arrhenius model must fit the data over a range of $\alpha$ 's in order to back out a single set of kinetic parameters, which raises the question of whether the mechanisms at higher temperatures are the same as lower temperatures. Ultimately, the biggest concern for both of these models is whether the mechanisms of water release under these temperatures and pressures can be extrapolated down to milder temperatures and pressures.

\section{Model Validation}

Figure 4 compares the results of an oven drying test ${ }^{26}$ to predictions from the isoconversional analysis and the $\mathrm{n}^{\text {th }}$-order Arrhenius model. In the oven drying test, LX-17 (92.5\% TATB, 7.5\% Kel-F 800) molding powder was laid out in a drying tray at a thickness of $38-50 \mathrm{~mm}$ and placed in preheated ovens $\left(90,100\right.$, and $\left.120{ }^{\circ} \mathrm{C}\right)$. Samples were extracted from the trays periodically between 0 and 96 hours and stored in glass vials until they were analyzed using the Karl-Fischer method. Both wet and dry aminated TATB-formulations were studied in the oven drying test.

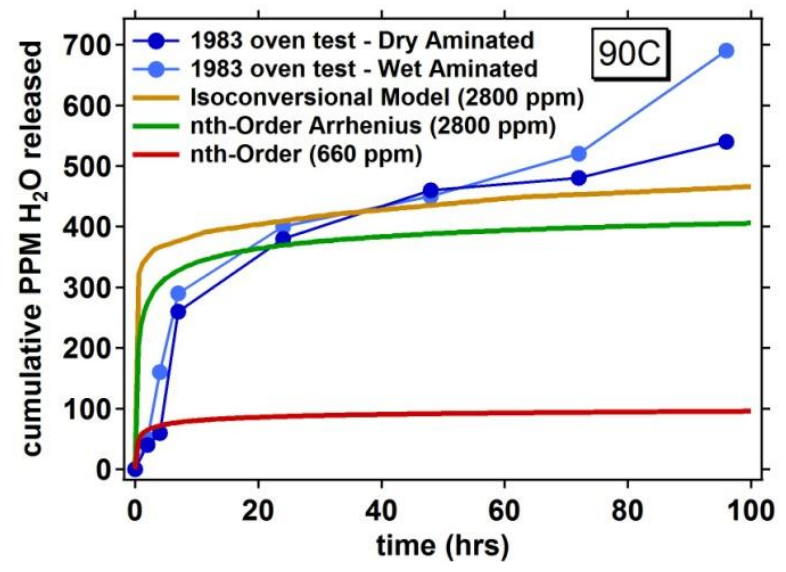

FIGURE 4. Comparison of isoconversional (brown lines) and $\mathrm{n}^{\text {th }}$-order Arrhenius model (green lines) predictions to oven drying test results by Stull et al.'s study of LX-17 (blue points/lines). The red line corresponds to the $\mathrm{n}^{\text {th }}$-order model adjusted to the initial water content measured in Stull's study (i.e. $660 \mathrm{ppm}) .^{26}$ 
Comparison of the experimental results with the model predictions in Figure 4 indicate that both models do a reasonable job of predicting the amount and rate of water release. At $90{ }^{\circ} \mathrm{C}$, one would only expect moisture release via the mechanisms in the first stage (referring to Figure 2), i.e. the lower barrier process. For completeness, however, the predictions incorporated the kinetics of both stages with the expectation that the high barrier of the second stage reaction will render it uninfluential in these predictions. The modeling predicts a rapid release of moisture in the first hour; in contrast, experiments demonstrate a rapid rise in the first $10 \mathrm{hrs}$. The likely reason for this difference is that the model assumed an isothermal reaction from time zero whereas the oven tests involved placing room temperature trays of sample into hot ovens. One would expect a small lag in moisture release as the sample temperature equilibrates with the oven temperature; the equilibration depends on the thickness, density, and thermal transport properties of the powder.

These models are best suited for predicting the relative population of water released as a function of the thermal history; the actual amount of water released depends on the initial concentration. In Figure 4, the model predictions are based on an initial water concentration of $2800 \mathrm{ppm}$, which is the maximum amount of water released in the TPD experiments. When the initial concentration of water from Stull's experiments (i.e. $660 \mathrm{ppm}$ ) was used with the $\mathrm{n}^{\text {th }}$-order Arrhenius model, the resulting prediction (red line in Figure 4) does not match the experimental data. One likely explanation is that Stull's method of measuring water content may have a systematic error. In the Karl-Fischer method, solid samples are dispersed or dissolved in a non-aqueous solvent and water is titrated. ${ }^{27}$ It is well known that TATB has very low solubility in most solvents, ${ }^{28}$ hence a method was developed in which the TATB-formulations were dispersed into a solvent via a Waring blender. ${ }^{27}$ The method developers acknowledged the fact that fine particles settle out of the suspension and that this method, while precise, has not been proven to be accurate. ${ }^{27}$ We surmise that the fine precipitate particles may still have water trapped in them and that the Karl-Fischer method may not be able to accurately measure the total concentration of water resulting in underestimates. Since the kinetic model requires input of the actual initial water concentration in the sample to predict the amount of water released (the output scales with the initial water concentration), 
inputting the value given by Karl Fisher analysis is expected to result in underestimation of the water release.

Figure 5 shows the results of an oven drying test of PBX-9502 performed by Stull et al. ${ }^{29}$ In this study, pressed pellets of PBX-9502 (9.5 mm diameter x $9.5 \mathrm{~mm}$ tall) were dried in a pre=heated, forced draft oven at $70{ }^{\circ} \mathrm{C}$ and water analysis was tested via Karl-Fischer. It is clear in Figure 5 that the isoconversional and $\mathrm{n}^{\text {th }}$-order Arrhenius predictions are orders of magnitude different in the predicted amount of water released; however, the release rate is quite accurate. In order to illustrate this, the initial water concentration was scaled to $21,000 \mathrm{ppm}$ to achieve better agreement with the Stull 1984 experiments. The scaled data using the $\mathrm{n}^{\text {th }}$-order model is shown in the red line in Figure 5. It is evident from comparison of the red line with the isothermal data (blue points and lines) that the kinetic model(s) predict the rate of water release accurately. The large disparity in moisture between these PBX-9502 samples and our experiment could be due to sample variability. As was discussed in the context of Figure 4, an accurate estimate of the initial water concentration in these samples would allow for accurate predictions of not only the rate but the actual amount of water release under a given set of conditions.

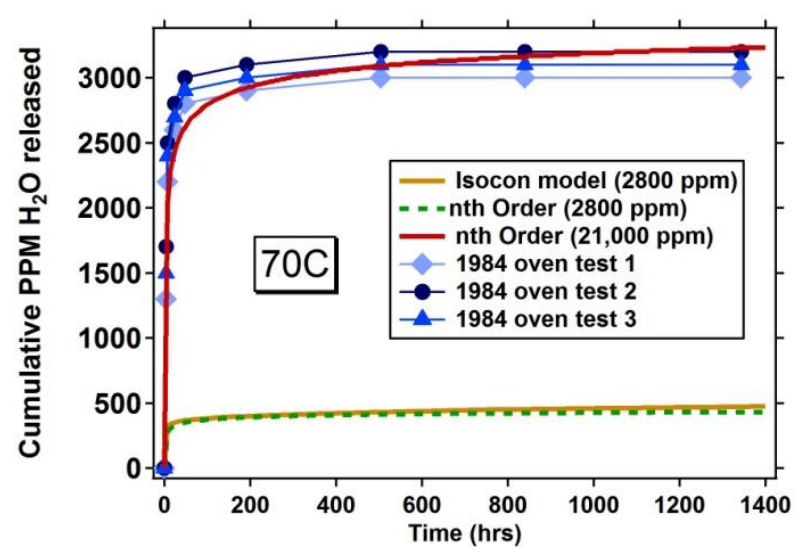

FIGURE 5. Comparison of isoconversional (brown lines) and $n^{\text {th }}$-order Arrhenius model (green dashed lines) predictions to oven drying test results by Stull et al.'s study of PBX-9502 at $70{ }^{\circ} \mathrm{C}$ (blue points/lines). ${ }^{29}$ The red line corresponds to the $\mathrm{n}^{\text {th }}$-order model scaled to 21,000 ppm for initial water concentration. 
Both the isoconversional model and the $\mathrm{n}^{\text {th }}$-order Arrhenius model were compared to a number of other sets of experimental data (e.g. different temperatures for Stull et al.'s oven drying test ${ }^{26}$ ). In all cases, the rate of water release was similar between the models and the experiments; however, the actual amount of water varied due to variability in initial water content.

\section{CONCLUSIONS}

Numerous studies have explored the possible production of water as a reaction product in the decomposition of TATB, yet no study has quantified the rates or explored the avenues of water release via non-decomposition mechanisms. The results from this study provide a kinetic model to guide other studies in drying TATB-samples prior to experimentation. More importantly, the results of this work indicate that moisture is deeply embedded in TATB formulations. In fact, only by subliming the TATB was it possible to release much of the latent water within the samples. It is difficult to imagine this latent water will ever be eliminated from TATB samples through drying methods regardless of how long the sample is dried prior to an experiment. Hence, the results of this study indicate the observation of water amongst the decomposition products does not necessarily mean that water is formed during the decomposition. This is not to say that the inter/intramolecular $\mathrm{H}$-atom transfer mechanism is not a valid mechanism. In fact, numerous studies have provided solid evidence for this mechanism via the observation of other products (e.g. furazan- and furoxan-derivative of TATB) or via deuterium labeled TATB. However, the exact conditions that favor the $\mathrm{H}$-atom transfer mechanisms versus the $\mathrm{C}-\mathrm{NO}_{2}$ bond homolysis and/or rearrangement are still under investigation and researchers should take care in assigning a mechanism based exclusively on the observation of water.

\section{ACKNOWLEDGMENT}

This work was performed under the auspices of the U.S. Department of Energy by Lawrence Livermore National Laboratory under Contract DE-AC52-07NA27344. 


\section{Supporting Information Available}

Isoconversional parameters in tabular form. This information is available free of charge via the Internet at http://pubs.acs.org.

\section{REFERENCES}

(1) Land, T. A.; Siekhaus, W. J.; Foltz, M. F.; Behrens Jr., R. "Condensed-Phase Thermal Decomposition of TATB Investigated by Atomic Force Microscopy (AFM) and Simultaneous Thermogravimetric Modulated Beam Mass Spectrometry (STMBMS)"; Tenth International Detonation Symposium, 1993, Boston, MA.

(2) Sharma, J.; Forbes, J. W.; Coffey, C. S.; Liddiard, T. P. J. Phys. Chem. 1987, 91, 5139.

(3) Makashir, P. S.; Kurian, E. M. Journal of Thermal Analysis 1996, 46, 225.

(4) Rogers, R. N.; Janney, J. L.; Einger, M. H. Thermochimica Acta 1982, 59, 287.

(5) Wu, C. J.; Fried, L. E. J. Phys. Chem. 2000, 104, 6447.

(6) Glascoe, E. A.; Zaug, J. M.; Armstrong, M. R.; Crowhurst, J. C.; Grant, C. D.; Fried, L. E. J. Phys. Chem. A 2009, 113, 5881.

(7) Brill, T. B.; James, K. J. Chem. Rev. 1993, 93, 2667.

(8) Sharma, J.; Garrett, W. L.; Owens, F. J.; Vogel, V. L. J. Phys. Chem. 1982, 86, 1657.

(9) Sharma, J.; Owens, F. J. Chem. Phys. Lett. 1979, 61, 280.

(10) Kakar, S.; Nelson, A. J.; Treusch, R.; Heske, C.; van Buuren, T.; Jimenez, I.; Pagoria, P.; Terminello, L. J. Phys. Rev. B 2000, 62, 15666.

(11) Brill, T. B.; James, K. J. J. Phys. Chem. 1993, 97, 8752.

(12) Dinh, L. N.; Burnham, A. K.; Schildbach, M. A.; Smith, R. A.; Maxwell, R. S.; Balazs, B.; McLean II, W. J. Vac. Sci. Technol. A 2007, 25, 597.

(13) Friedman, H. L. J. of Polymer Sci. Part C 1964, 6, 183.

(14) Galwey, A. K.; Brown, M. E. Thermal Decomposition of Ionic Solids; Elsevier Science B.V.: Amsterdam, 1999.

(15) Burnham, A. K.; Dinh, L. N. J. of Thermal Analy. and Calor. 2007, 89, 479.

(16) Braun, R. L.; Burnham, A. K. Kinetics05; The Regents of the University of California: Livermore, CA, 2006.

(17) Cady, W. E.; Caley, L. E. "Properties of Kel F-800 Polymer," Lawrence Livermore National Laboratory, 1977.

(18) Maienschein, J. L.; Garcia, F. Thermochimica Acta 2002, 384, 71.

(19) Kolb, J. R.; Rizzo, H. F. Propellants, Explosives, Pyrotechnics 1979, 4, 10.

(20) Willey, T. M.; van Buuren, T.; Lee, J. R. I.; Overture, G. E.; Kinney, J. H.; Handly, J.; Weeks, B. L.; Ilavsky, J. Propellants, Explosives, Pyrotechnics 2006, 31, 466.

(21) Dobratz, B. M. "The Insensitive High Explosive Triaminotrinitrobenzene (TATB): Development and Characterization - 1888 to 1994," Los Alamos National Laboratory, 1995.

(22) Burnham, A. K.; Braun, R. L. Energy and Fuels 1999, 13, 1.

(23) Burnham, A. K. Chem. Eng. Journal 2005, 108, 47.

(24) Rosen, J. M.; Dickinson, C. J. of Chem. Eng. Data 1969, 14, 120.

(25) Steinfeld, J. I.; Francisco, J. S.; Hase, W. L. Chemical Kinetics and Dynamics, 2nd Ed.; Prentice Hall: Upper Saddle River, NJ, 1999. 
(26) Stull, T. W.; Ashcraft, R. W. "Drying Studies of LX-17 at 90, 100, and 120C," Mason and Hanger- Silas Mason Co. Inc, Pantex Plant, 1983.

(27) Sandoval, J. "Feasibility of Moisture Analysis in TATB Utilizing Karl Fischer Method," Mason and Hanger - Silas Mason Co. Inc., Pantex Plant, 1979.

(28) Selig, W. "Estimation of the Solubility of 1,3,5-triamino-2,4,6-trinitrobenzene (TATB) in Various Solvents," Lawrence Livermore National Laboratory, 1977.

(29) Stull, T. W. "Available Moisture in PBX-9502 at 70 C," Mason and Hanger - Silas mason Co. Inc. Pantex Plant, 1984. 